\title{
Molecular Diagnostics in Tuberculosis
}

\section{Vincent Chi-Chung CHENG ${ }^{1}$, Wing Wai YEW ${ }^{2}$, Kwok Yung YUEN ${ }^{1}$}

Centre of Infection, The University of Hong Kong ${ }^{1}$, and Tuberculosis \& Chest Unit, Grantham Hospital $^{2}$, Hong Kong Special Administrative Region, China Correspondence to:

K.Y. Yuen, Centre of Infection and Immunology, The University of Hong Kong, University Pathology Building, Queen Mary Hospital, Hong Kong Special Administrative Region, China (Tel: +852-28554892, Fax: +852-28551241, E-mail: kyyuen@hkucc.hku.hk)

Keywords: Mycobacterium tuberculosis, molecular diagnosis, polymerase chain reaction, resistance, outbreak.

Word count: 3585

Conflict of Interest Statement: None declared

Financial support: None 


\begin{abstract}
Molecular diagnostics in tuberculosis have enabled rapid detection of Mycobacterium tuberculosis complex in clinical specimens, identification of mycobacteria species, detection of drug resistance, and typing for epidemiological investigation. In laboratory diagnosis of tuberculosis, nucleic acid amplification (NAA) test is rapid, specific but not as sensitive as mycobacterial cultures. The primary determinant of successful NAA testing of tuberculosis depends on the shedding of mycobacterial DNA in secretions from caseating granuloma and its dissemination into sterile body fluids or tissue biopsies. In multibacillary diseases with high mycobacterial load, a positive Ziehl-Neelsen (ZN) smear with positive NAA is diagnostic of active tuberculosis whereas a positive ZN smear with a negative NAA in the absence of inhibitors would indicate non-tuberculous mycobacterial diseases. The role of NAA test is more important in paucibacillary diseases with low mycobacterial load. But the presence of PCR inhibitors especially in extrapulmonary specimens may produce false negative results. Although part of this inhibitor problem can be overcome by extra-extraction steps, it invariably leads to the loss of more mycobacterial DNA. To circumvent this problem, a brief culture augmentation step before NAA to enhance the mycobacterial load with concomitant dilution of inhibitors can maintain the sensitivity without excessively increases in turnaround time.
\end{abstract}




\section{INTRODUCTION}

Mycobacterium tuberculosis has infected one-third of the world's population, and is currently causing 8 million new cases as well as 2 million fatalities per year (1). In both developing and developed countries, a resurgence of tuberculosis including multidrugresistant tuberculosis (MDR-TB) has occurred among high-risk populations such as the human immunodeficiency virus-infected patients (1). The control of tuberculosis mainly depends on rapid and accurate diagnosis, provision of effective antituberculous treatment, and thorough contact tracing. Before the introduction of molecular biology into diagnostic mycobacteriology, direct microscopy using a Ziehl-Neelsen smear of early morning sputum was the only way of making a rapid diagnosis. However, a positive smear requires the presence of about $10^{4}$ acid-fast bacilli (AFB) per ml of sputum (2). Although the sensitivity could be improved by concentrating sputum sediment and applying auramine $\mathrm{O}$ fluorescent stain, direct microscopy cannot distinguish between $M$. tuberculosis and nontuberculous mycobacteria. Therefore, a positive culture of $M$. tuberculosis remains the gold standard for diagnosis of the disease. Unfortunately, growth on the most affordable solid culture medium, the Lowenstein-Jensen (LJ) medium usually takes 4-6 weeks. Moreover, most clinical specimens for culture, such as sputum and bronchoalveolar lavage require prior decontamination with $\mathrm{N}$-acetyl-L-cysteine and $2 \%$ sodium hydroxide which invariably causes a substantial decrease in the number of colony-forming-units of $M$. tuberculosis (2). Sensitivity is augmented by the use of an broth culture medium such as BacT/ALERT system, Mycobacterial Growth Indicator Tube (MGIT) (containing modified Middlebrook 7H9 broth), or BACTEC 460TB system, and their automated analogues: MGIT 960 or BACTEC $9000 \mathrm{MB}$, respectively 
$(3,4,5,6)$. The mean time to detection of $M$. tuberculosis in smear-positive specimens was 13.3 days by the MGIT 960 (range 4-39) and 12.7 days by the BACTEC 9000 MB (range 7-21) respectively (7). Reports of rapid diagnosis of tuberculosis by the detection of various mycobacterial components have not lived up to expectations. The employed tools included gas chromatography-mass spectrometry assay for detection of tuberculostearic acid, and enzyme-linked immunosorbent assay (ELISA) for detection of glycolipid antigen, lipoarabinomannan antigen, and Antigen 60 of M. tuberculosis $(8,9,10)$.

Molecular diagnostics in tuberculosis have enabled (i) direct detection of M. tuberculosis complex in clinical specimens; (ii) identification of mycobacteria, (iii) detection of drug resistance of $M$. tuberculosis, and (iv) DNA typing to address issues like reactivation of disease versus exogenous reinfection, and to track transmission and internal laboratory contamination. These technological advancements are not intended to replace the conventional tests, but would rather serve as important complementary tools in the management of tuberculosis.

\section{NUCLEIC ACID AMPLIFICATION TESTS FOR RAPID DIAGNOSIS OF TUBERCULOSIS IN CLINICAL SPECIMENS}

In order to diagnose tuberculosis rapidly, manufacturers have developed nucleic acid amplification (NAA) tests specific for M. tuberculosis complex for its direct detection from sputum specimens. Of the two commercially available NAA tests approved by U.S. 
Food and Drug Administration (FDA): Amplified Mycobacterium tuberculosis Direct Test (MTD; Gen-Probe, San Diego, California, US) and COBAS AMPLICOR $M$. tuberculosis assay (Roche Diagnostics, Mannheim, Germany), had excellent performance when used for testing smear-positive specimens (with sensitivity $>95 \%$ and specificity $=$ $100 \%$ ). The sensitivity was lower ( $83 \%$ to $85 \%$ ) when used for testing smear-negative specimens, though the specificity stayed high (99\%) (11). Basing on these data, the FDA only recommended the use of NAA tests for smear-positive respiratory specimens from patients who had not received antituberculous drugs for seven or more days, or within the last 12 months (12). Following the initial FDA clearance, Gen-Probe enhanced the performance of MTD. A large-scale study further revealed the overall sensitivity, specificity, positive predictive value (PPV) and negative predictive value (NPV) of the enhanced MTD to be $94.7 \%, 100 \%, 100 \%$, and $98.4 \%$, respectively for respiratory specimens (13). The corresponding values were $89.4 \%, 100 \%$, $100 \%$, and $98.3 \%$, respectively for smear-negative respiratory specimens. This enhanced version of the MTD was eventually approved by the FDA for testing respiratory specimens, regardless of the smear status. COBAS AMPLICOR M. tuberculosis assay maintains a reasonable sensitivity and specificity in smear positive respiratory specimens after the initial FDA clearance $(14,15,16,17)$. However, it is limited by slow block cycler amplification process and time-consuming colorimetric detection of the amplification products, which may affect the turn around time. Recently, COBAS AMPLICOR M. tuberculosis assay integrates with real-time techniques using the LightCycler 2.0 instrument (Roche Applied Science, Penzberg, Germany). The procedure for template DNA extract remains the same as that of the COBAS AMPLICOR assay. With the use of LightCycler instrument to 
detect the amplification products, the turnaround time can be shortening. In 146 clinical specimens being evaluated, good agreement (100\% sensitivity, $98.6 \%$ specificity) were shown between the LightCycler and COBAS AMPLICOR assays (18).

The early studies on NAA tests were largely laboratory-based, emphasizing culture results as a major endpoint, and neglected integration of available clinical information into the decision making process (12). In reality, it is mandatory to consider the degree of clinical suspicion for tuberculosis in determining the clinical utility of NAA tests. There have been a number of subsequent studies addressing the use of NAA in the clinical setting. In one prospective study, the diagnostic yield of PCR in patients admitted to rule out pulmonary tuberculosis was studied (19). Among 85 patients, 27 patients had cultures positive for M. tuberculosis, 12 were smear-positive. A positive PCR on at least one of two specimens collected in the first 24 hours was 85 and $74 \%$ sensitive, and 88 and 93\% specific for tuberculosis by the in-house and Roche techniques, respectively. Sensitivity in smear-negative patients was 73 and 53\%, respectively. Thus, PCR was found to be a useful tool to evaluate patients for tuberculosis within the first hospital day. In a multicenter prospective trial, a total of 338 patients with symptoms and signs consistent with active pulmonary tuberculosis and complete clinical diagnosis were stratified by the clinical investigators to be at low ( $\leq 25 \%)$, intermediate (26 $-75 \%)$, or high (>75\%) relative risk of having tuberculosis (20). Based on a comprehensive clinical diagnosis, the sensitivity of the enhanced MTD test was $83 \%, 75 \%$, and $87 \%$ for low, intermediate, and high clinical suspicion of tuberculosis, respectively, and the corresponding specificity was $97 \%, 100 \%$, and $100 \%$. PPV of the enhanced MTD test 
was 59\% (low), 100\% (intermediate), and 100\% (high), compared with 36\%, 30\% and 94\%, respectively for the AFB smear. The investigators concluded that for complex diagnostic problems like tuberculosis, clinical risk assessments can provide important information regarding predictive values more likely to be experienced in clinical practice.

Aside from the commercial NAA tests, a number of in-house studies have been developed over the years. On the whole, the commercial tests have comparable sensitivity and specificity with the in-house tests for respiratory specimens $(21,22)$. In addition to the original intention for facilitating early diagnosis of pulmonary tuberculosis, the NAA tests have been extensively studied in patients with extrapulmonary tuberculosis by either commercial kits or in-house assay (table 1) (22-50). However, the number of publications is too small to allow a meaningful analysis, except for a few clinical entities. For tuberculous meningitis, there have been quite a number of reports with test performance somewhat at variance $(34,36,37,51)$. In one study, the initial low sensitivity of $33 \%$ in cerebrospinal fluid could be elevated to $83 \%$ by decreasing the cutoff values for positive results of the MTD (34). In a large scale study from Sweden that analyzed 154 cerebrospinal fluid samples using the Cobas Amplicor test (Roche), the sensitivity, specificity, PPV and NPV were 55.6\%, 97.2\%, 55.6\% and 97.2\%, respectively (36). In the most recently published systematic review and meta-analysis on the diagnostic accuracy of NAA tests for tuberculous meningitis (37), it has been found that the summary estimates in 14 studies utilizing commercial NAA tests were: sensitivity 0.56 and specificity 0.98 . In the 35 studies using in-house tests, the summary accuracy could not be established with confidence because of wide variability in test accuracy. Thus, on 
current evidence, commercial NAA tests show a potential role in confirming the diagnosis of tuberculous meningitis, although their overall low sensitivity possibly precludes exclusion of the disease with certainty (37). For pleural effusion, one comparative study of Amplicor PCR, and conventional smear and culture methods has not shown a significant difference in the accuracy of diagnosis (29). On the other hand, some other studies using in-house PCR have yielded rather encouraging sensitivities and specificities of $\geq 70 \%$ and $\geq 90 \%$, respectively (30,31). A recent study using real-time PCR assay in fine-needle aspirates and tissue biopsy specimens for diagnosing mycobacterial lymphadenitis revealed a sensitivity and specificity of $72 \%$ and $100 \%$, respectively (27). The former is better than conventional staining and culture techniques. Thus, this NAA test can provide useful support for clinical decision making in children with lymphadenitis.

The more recently developed BDProbeTEC ET system (BD Biosciences, Sparks, Md) is an automated system characterized by simultaneous DNA amplification (strand displacement amplification) and real-time fluorometric detection. An early evaluation of this direct detection system has suggested its usefulness (52, 53). A recent study of 1131 clinical specimens (735 respiratory specimens and 396 nonrespiratory specimens) (125 M. tuberculosis culture-positive: 42 smear-positive), showed that the overall sensitivity, specificity, PPV, and NPV were respectively 90.3\%, 96.9\%, 78.3\%, and 98.9\% (54). A comparative study on the performance assessment of the enhanced-MTD test and the BDProbeTec system has also been performed (55). For the enhanced-MTD assay, the sensitivity and specificity were $88 \%$ and $99.2 \%$ respectively for respiratory specimens, 
and $74.3 \%$ and $100 \%$ respectively for extrapulmonary specimens. The corresponding values for BDProbeTec were $94.5 \%$ and $99.6 \%$ for respiratory specimens, and 92.3\% and $100 \%$ for extrapulmonary specimens, respectively. The difference in sensitivity between these two systems was possibly due to better detection of inhibitors by the BDProbeTec system with an internal amplification control. A recent study has further suggested the BDProbeTec ET System can be very useful for rapid detection of $M$. tuberculosis complex , especially in smear-negative respiratory specimens including pleural fluid (56). In this study, the sensitivity for smear-positive and smear-negative specimens was $100 \%$ and $81.5 \%$, respectively. While data have been limited for nonrespiratory specimens, a recent study revealed high sensitivity (84.7\%) attained in the diagnosis of tuberculous meningitis (57).

Data concerning the impact of the $M$. tuberculosis complex NAA tests on patient outcome have so far been gathered from uncontrolled studies or observations only, and are not based on well-designed clinical trials. The impact of the NAA tests on patient outcome mainly depends on the status of the AFB smear. In smear-positive patients, hospital infection control and public health resources are largely affected, regarding drug therapy and isolation of hospitalized patients for air-borne infections, as well as contact investigations. Appropriate use of isolation beds is especially important in high prevalence areas, regional outbreaks, or where such beds are scarce. In smear-negative patients, the NAA test has a greater potential in influencing the outcome of patients regarding treatment, and avoiding the need for costly and/or risky diagnostic investigations/procedures. Thus, molecular diagnostics of M. tuberculosis complex has a 
potential to improve clinical care through a substantial reduction in the time required for mycobacterial detection, and may provide material savings in the overall cost of care of a patient. A cost-effectiveness analysis of the MTD (Gen-probe) direct test as used routinely on smear-positive respiratory specimens has been published recently (58). The authors considered that while routine MTD testing of smear-positive specimens would not be expected to have cost saving for most individual hospitals, centralized reference laboratories might be able to implement MTD in a cost-effective manner across a wide range of settings. Prospective studies are required concerning the cost-effectiveness of NAA tests in patients suspected to have tuberculosis. While awaiting more clues for evidence-based practice, one pragmatic approach at present is still to concentrate using NAA tests for smear-positive patients with intermediate or low probability of tuberculosis, and smear-negative patients with high or intermediate clinical suspicion of the disease.

Although the NAA tests provide a rapid diagnosis for pulmonary and extrapulmonary tuberculosis, the sensitivity is still far from ideal. The limitation of the utility of NAA tests is largely attributed to the lack of shedding from patients with tuberculosis and the susceptibility of the amplification reaction to the inhibitor. Secretion of antigens from the bacterial cell of $M$. tuberculosis invariably excites a granulomatous inflammation in immunocompetent hosts which produces a walling off effect by the epithelioid cells and fibroblast at the site of infection. No bacteria will be shed and excreted via the luminal passages such as the airway into the exterior or potential body cavities such as peritoneum, pericardium, pleura, synovium, and arachnoids. Shedding only starts to 
occur when the granulomatous inflammation is so severe that caseous necrosis has occurred with erosion into the mucosal lumen or coelomic cavity. In the case of the airway, the necrotic material carrying the AFB is carried by the mucociliary blanket and coughed into the environment. It is usually at this stage that a diagnosis can be made in an immunocompetent host using either culture or NAA test. It is also important to note that extrapulmonary specimens such as whole blood and various body fluids could be more useful clinical specimens in immunosuppressed hosts where mycobacterial dissemination readily occurs without the walling off effect of granulomatous inflammation. As expected, studies have shown a reasonable sensitivity of NAA test using peripheral blood in AIDS patients with tuberculosis (45).

Although the advantage of NAA over culture is that the sensitivity is not decreased by the prior decontamination step, this advantage is offset by inhibitors of the polymerase enzyme. The incidence of such inhibitors varies from $4 \%$ in pulmonary to $18.6 \%$ in extrapulmonary specimens (59). Part of this inhibitor problem can be overcome by refining the nucleic acid extraction step. But these extra-extraction steps invariably lead to the loss of more mycobacterial DNA. This is a serious problem in extrapulmonary tissue specimens where inhibitors are especially abundant (59). This may be circumvented by a short culture augmentation step with concomitant dilution of inhibitors. A brief culture of 2 to 3 days on LJ medium significantly increased the sensitivity of NAA tests in tissue samples exerting PCR inhibition from $63 \%$ to $92 \%$ (60). False positive results from NAA tests could be minimized by automated testing, good laboratory practice, and the use of uracil-N-glycosylase (UNG) and dUTP-UNG 
$(2,61)$. However, biological false positive has also been reported as a result of the shedding of dead mycobacteria after adequate antituberculous treatment (62). Except for the turnaround time, the initial expectations that these NAA tests are at least as rapid as the ZN smear, more sensitive and specific than the smear, more sensitive than the culture, especially those smear negative specimen from extrapulmonary sites where the diagnosis is always difficult due to the paucibacillary nature of the disease, have not been fulfilled (63).

\section{RAPID IDENTIFICATION OF MYCOBACTERIA BY MOLECULAR TECHNIQUES}

Identification of mycobacteria by growth characteristics and conventional biochemical tests takes many weeks. The CDC has recommended use of more rapid identification methods, such as nucleic acid probes, the NAP (p-nitro- $\alpha$-acetylamino- $\beta$ hydroxypropiophenone) test, and high-performance liquid chromatography (64).

Several systems exist for the rapid identification of mycobacterial species from cultured isolates (64). The MicroSeq 500 system (Applied Biosystems, Foster City, California, US) is an assay based on sequencing a portion of the $16 \mathrm{~S}$ rDNA gene $(65,66,67)$. It is time-consuming to perform and requires sophisticated instrumentation for data analysis. The AccuProbe assay (Gen-Probe, San Diego, California, US), a chemiluminescent DNA probe, involving hybridization with species-specific probes, is highly specific. But the test is only able to identify a limited number of species (68). Like MicroSeq 500 system, it cannot differentiate $M$. tuberculosis from the other species in the complex. DNA strip 
assays based on the reverse hybridization of PCR products to oligonucleotide probes bound on a membrane strip can be applied to identify myccobacterial species. Two commercial preparations of DNA strip assay are available for laboratory diagnosis (68). Inno-LiPA Mycobacteria (Innogenetics NV, Ghent, Belgium) identifies mycobacteria by the 16 to 23S rDNA spacer region of Mycobacterium species (69) and GenoType Mycobacteria (Hain Lifescience, Nehren, Germany) identifies mycobacteria by $23 \mathrm{~S}$ rDNA of Mycobacterium species (70). Both can also identify M. tuberculosis from clinical isolates $(70,71)$ or broth culture systems $(72)$, but does not allow differentiation among members of the $M$. tuberculosis complex. A single test can identify a range of species (73). Inno-LiPA assay has been recently improved (Inno-LiPA Mycobacteria v2) by increasing the number of identifiable mycobacterial species to 16 (74). GenoType assay can identify 13 clinically important mycobacterial species. In a prospective evaluation of 178 clinical isolates, GenoType assay produced an overall agreement of 89.3\% with AccuProbe assay and 16s rDNA sequencing (70). Other rapid identification method included PCR amplification-restriction analysis of the rpoB DNA which can detect pathogenic mycobacteria including $M$. tuberculosis complex in clinical specimens (75).

Furthermore, an extension of the principle of solid phase detection of nucleic acids has been developed. Using high-density DNA probe arrays on a microchip, the system can provide rapid strain identification, as well as, assessment of drug resistance in cultured isolates $(76,77)$. While these microarrays are technologically advanced, the associated cost can be great. One simpler way is to use the peptide nucleic acids probes as an in situ 
hybridization assay by a fluorescent stain format. Peptide nucleic acids are DNA-like structures in which the sugar-phosphate backbones are replaced with peptide-like structures. The binding of peptide nucleic acid to DNA is sequence specific, and the interaction is stronger than that of a DNA-DNA interaction. This technology has been found to work well for cultured isolates, and formalin-fixed histological samples $(78,79)$.

\section{RAPID DRUG SUSCEPTIBILITY TESTING USING MOLECULAR TECHNIQUES}

Giving an effective antituberculous drug combination is as important as making a rapid and accurate diagnosis of tuberculosis. Without a rapid drug-susceptibillity testing method, most clinicians are prescribing a standard regimen empirically for patients with no known risk factors for drug-resistant disease. Traditionally, drug-resistance testing requires the growth of sufficient bacterial colonies in order to allow standardization of inoculums used in the agar proportion method (2), which usually takes another 2 weeks. The turnaround time is shortened to only 4 days with the BACTEC 460TB methods, which incorporates standard dilution of antituberculous drugs (isoniazid, rifampicin, pyrazinamide, ethambutol, and streptomycin) in the broth medium and monitor the growth curve after inoculation (2).

With unraveling of the genetic basis of antituberculous drug resistance through identification of the main genes in question (80), namely rpoB (rifampicin), katG (isoniazid), inhA (isoniazid and ethionamide), ahpC (isoniazid), pncA (pyrazinamide), embB (ethambutol), rrs (streptomycin), and rpsL (streptomycin) and gyrA 
(fluoroquinolone), various molecular techniques for detection of drug resistance (largely against rifampicin, isoniazid, pyrazinamide and streptomycin) in M. tuberculosis have been evaluated. These principally include direct DNA sequencing (81), heteroduplex (82), and restriction fragment length polymorphism (83), as well as oligonucleotide arrays (84). Two commercial forms of the molecular assays, namely INNO-LiPA Rif.TB (Innogenetics, Belgium) and MisMatch Detect II (Ambion, U.S.A.) have performed well by correlating with standard methods of detection of $M$. tuberculosis and rifampin susceptibility testing in $94.7 \%$ and $100 \%$ smear-positive respiratory specimens, respectively (85). For the cultured isolates, the correlations reached $100 \%$. The former technique is a line probe assay based on the reverse hybridization principle. The latter represents a RNA/RNA duplex, base pair-mismatch assay. Direct DNA sequencing and DNA arrays also appear very promising for future use due to high sensitivity and specificity. In recent years, there have been additional reports on direct detection of rifampicin and isoniazid resistance rapidly in $M$. tuberculosis strains present in clinical specimens. Most of the techniques embrace the use of improved PCR amplification, such as real-time PCR (86) or allele-specific on-chip PCR (87). Another new development in recent years has involved the molecular beacons. These are molecules that emit light following upon a chemical reaction involving a colored fluorophore (88). Such molecular beacon assays based on binding of DNA primers with specific targets in PCR amplicons can provide a rapid and sensitive method of diagnosing drug resistance (89). However, application of DNA arrays and molecular beacons is associated with high cost. A recent study has described the potential utility of the peptide nucleic acid probes in 
detecting mutated KatG and rpoB genes in M. tuberculosis (90). This study utilizes the PCR-ELISA format and is likely to be more economical.

\section{UTILITY OF MOLECUAR FINGERPRINTING IN TUBERCULOSIS}

Tuberculosis often has a long incubation period which makes outbreak investigations more difficult than for other acute respiratory infections. Discriminatory typing methods would have an important place in the confirmation of clusters in outbreak investigations especially in areas where the disease is highly endemic. Strain typing has been used in community or institutional outbreaks involving family households, prisons, laboratory cross-contamination and outbreaks due to drug-resistant strains $(91,92,93)$. These typing techniques are also important in the differentiation of reactivation or exogenous reinfection. At the national level such tests could also be used for the evaluation of regional control programs and will allow the design of more rational control measures. In the last 10 years, the most widely used technique is restriction fragment length polymorphism (RFLP) analysis of chromosomal DNA using IS6110, an insertion sequence found throughout the $M$. tuberculosis complex, typically in 5 to 20 copies (94). While general principles regarding interpretation of RFLP patterns are present, there are no universally accepted criteria. Besides, the analysis is labor-intensive and cannot be applied to strains with five or fewer copies of IS6110, which are not uncommon in some communities rendering this approach less useful (95). Other fingerprinting techniques that have been developed to complement RFLP analysis include blotting for polymorphic guanine-cytosine-rich sequences (96), substituting IS1081 (97) or other repeat sequences such as the variable-number tandem repeats (98), and spoligotyping (99). 


\section{OTHER POTENTIAL UTILITY OF MOLECULAR DIAGNOSTICS IN TUBERCULOSIS}

Molecular detection of mycobacterial DNA has also been investigated regarding its potential to predict treatment success, failure or relapse. Initially monthly qualitative PCR on sputum specimens were performed. The majority of the treated patients either did not produce sputum or have a negative PCR test by 6 months (62). Around 30\% had persistent positive test but most of these patients had extensive pulmonary disease, underlying medical problems (62). A small number of these persisters actually had known MDR-TB which accounted for the failure (62). Most of these persisters could be explained by the persistent shedding of dead AFB. Since microbial load is the result of the dynamic interaction between the microbe, the host defense and the drug treatment, a serial quantitative monitoring of the microbial load throughout the course of treatment may be important for both prognostic predictions and individualization of the regimen and duration in the long run. This is possible with the advent of the real time PCR using the LightCycler (100). However studies comparing the quantitation by AFB smear, colony counts and genome copies by quantitative PCR showed that the initial bacillary load are only well correlated before treatment. But the rate of disappearance of the AFB and the quantity of DNA did not correlate with the rate of decline of the viable colony count and therefore not useful for monitoring of the efficacy of drug treatment. This was not unexpected since positive smears are well known to persist for years in patients with severe cavitary disease leading to extensive lung destruction. The hard cell wall of mycobacteria may well have protected the microbial DNA from host enzymatic 
degradation. There were attempts to use relatively shorter lived mRNA encoding $85 \mathrm{kDa}$ protein for monitoring the progress (101). The clinical usefulness of such approach would await validation by quantitative PCR in larger clinical studies.

\section{MOLECULAR DIAGNOSTICS FOR HOST SUSCEPTIBILITY}

The future of the molecular diagnostic test for tuberculosis will no longer be confined to the bacterial genome. The unfolding of the human genome has led to the discovery of more susceptibility or resistance genes associated with tuberculosis (102). These genes are related to effective killing of intracellular mycobacteria or granuloma formation. The effector mechanisms include the iron scavenging function of transport proteins of macrophages which competes with the siderophores of mycobacterium, the activation of macrophage function by Vitamin D, the antigen presentation, and even the cytokines, cytokine receptors and intracellular signaling molecules which are part of the immunological pathway of activation for a T-cell helper-1 response (103). Important examples are the natural resistance associated macrophage protein (NRAMP-1), Vitamin D receptor, HLA-DR2 and HLA-DQB1 loci, on chromosome 15 and X $(104,105,106)$. Importance of the mutations involving the receptors IFN R1, IFN R2, STAT1, IL12R $\beta 1$ associated with interferon- $\gamma$ mediated immunity is uncertain in tuberculosis though they have been found to be linked to disseminated diseases due to atypical mycobacteriosis

and other intracellular pathogens $(107,108)$. The use of microarray for a host genome survey of tuberculosis susceptibility would not be too far from reality.

\section{CONCLUSION}


In the past decade, there has been an exuberant progress in the discovery and evaluation of new techniques in molecular diagnosis for tuberculosis. Many of these are likely to have major complementary roles to the conventional tests. Some technologies have opened up potentially novel approaches in the fight against this important infectious disease worldwide. As for new drugs, the use of these new diagnostics is also fraught with budgetary considerations. This is especially relevant in the developing world with heavy disease burdens and severely compromised resources. Thus, continuing efforts must be made to address the clinical applicability and cost-effectiveness of these novel tools in the strategic management of tuberculosis globally. 


\section{REFERENCES}

1. Frieden TR, Sterling TR, Munsiff SS, Watt CJ, Dye C. Tuberculosis. Lancet 2003; 362: 887-899.

2. Pfyffer GE, Brown-Elliott BA, Wallace RJ Jr. Mycobacterium: General characteristics, isolation, and staining procedures. In: Murray PR, Baron EJ, Jorgensen JH, Pfaller MA, Yolken RH, editors. Manual of Clinical Microbiology. 8th ed. Washington, D.C.: ASM press;2003:532-559.

3. Angeby KA, Werngren J, Toro JC, Hedstrom G, Petrini B, Hoffner SE. Evaluation of the BacT/ALERT 3D system for recovery and drug susceptibility testing of Mycobacterium tuberculosis. Clin Microbiol Infect. 2003;9:1148-52.

4. Hanscheid T, Monteiro C, Cristino JM, Lito LM, Salgado MJ. Growth of Mycobacterium tuberculosis in conventional BacT/ALERT FA blood culture bottles allows reliable diagnosis of Mycobacteremia. J Clin Microbiol. 2005;43:890-1.

5. Diraa O, Fdany K, Boudouma M, Elmdaghri N, Benbachir M. Assessment of the Mycobacteria Growth Indicator Tube for the bacteriological diagnosis of tuberculosis. Int J Tuberc Lung Dis. 2003;7:1010-2.

6. Tortoli E, Benedetti M, Fontanelli A, Simonetti MT. Evaluation of automated BACTEC MGIT 960 system for testing susceptibility of Mycobacterium tuberculosis to four major antituberculous drugs: comparison with the radiometric BACTEC 460TB method and the agar plate method of proportion. J Clin Microbiol. 2002;40:607-10.

7. Flanagan PG, Williams R, Paull A. Comparison of two automated systems for the isolation of mycobacteria from clinical specimens. Eur J Clin Microbiol Infect Dis 
1999; 18: 912-914.

8. Savic B, Sjobring U, Alugupalli S, Larsson L, Miorner H. Evaluation of polymerase chain reaction, tuberculostearic acid analysis, and direct microscopy for the detection of Mycobacterium tuberculosis in sputum. J Infect Dis 1992; 166: 11771180.

9. Okuda Y, Maekura R, Hirotani A, Kitada S, Yoshimura K, Hiraga T, Yamamoto Y, Itou M, Ogura T, Ogihara T. Rapid serodiagnosis of active pulmonary Mycobacterium tuberculosis by analysis of results from multiple antigen-specific tests. J Clin Microbiol 2004; 42: 1136-1141.

10. Tessema TA, Bjune G, Assefa G, Svenson S, Hamasur B, Bjorvatn B. Clinical and radiological features in relation to urinary excretion of lipoarabinomannan in Ethiopian tuberculosis patients. Scand J Infect Dis. 2002;34(3):167-71.

11. Woods GL. Molecular techniques in mycobacterial detection. Arch Pathol Lab Med. 2001;125:122-6.

12. American Thoracic Society Workshop. Rapid diagnostic tests for tuberculosis: what is the appropriate use? Am J Respir Crit Care Med 1997; 155: 1804-1814.

13. Gamboa F, Fernandez G, Padilla E, Manterola JM, Lonca J, Cardona PJ, Matas L, Ausina V. Comparative evaluation of initial and new versions of the Gen-Probe Amplified Mycobacterium Tuberculosis Direct Test for direct detection of Mycobacterium tuberculosis in respiratory and non-respiratory specimens. J Clin Microbiol 1998; 36: 684-689.

14. Reischl U, Lehn N, Wolf H, Naumann L Clinical evaluation of the automated COBAS AMPLICOR MTB assay for testing respiratory and nonrespiratory 
specimens. J Clin Microbiol. 1998;36:2853-60.

15. Gaudreau C, Sala E, Ruiz-Serrano MJ, Petersen H, Oostendorp LA, Burkardt H. Multicenter study of a commercial, automated polymerase chain reaction system for the rapid detection of Mycobacterium tuberculosis in respiratory specimens in routine clinical practice. Eur J Clin Microbiol Infect Dis. 2001;20:724-31.

16. Levidiotou S, Vrioni G, Galanakis E, Gesouli E, Pappa C, Stefanou D. Four-year experience of use of the Cobas Amplicor system for rapid detection of Mycobacterium tuberculosis complex in respiratory and nonrespiratory specimens in Greece. Eur J Clin Microbiol Infect Dis. 2003;22:349-56.

17. Fegou E, Jelastopulu E, Sevdali M, Anastassiou ED, Dimitracopoulos G, Spiliopoulou I. Sensitivity of the Cobas Amplicor system for detection of Mycobacterium tuberculosis in respiratory and extrapulmonary specimens. Clin Microbiol Infect. 2005;11:593-6.

18. Burggraf S, Reischl U, Malik N, Bollwein M, Naumann L, Olgemoller B. Comparison of an internally controlled, large-volume LightCycler assay for detection of Mycobacterium tuberculosis in clinical samples with the COBAS AMPLICOR assay. J Clin Microbiol. 2005;43:1564-9.

19. Cohen RA, Muzaffar S, Schwartz D, Bashir S, Luke S, McGartland LP, Kaul K. Diagnosis of pulmonary tuberculosis using PCR assays on sputum collected within 24 hours of hospital admission. Am J Respir Crit Care Med 1998; 157: 156-161.

20. Catanzaro A, Perry S, Clarridge JE, Dunbar S, Goodnight-White S, LoBue PA, Peter C, Pfyffer GE, Sierra MF, Weber R, Woods G, Matthews G, Jonas V, Smith K, Della-Latta P. The role of clinical suspicion in evaluating a new diagnostic test for 
active tuberculosis: results of a multicenter prospective trial. JAMA 2000; 283: 639-645.

21. Huang TS, Liu YC, Lin HH, Huang WK, Cheng DL. Comparison of the Roche AMPLICOR MYCOBACTERIUM assay and Digene SHARP Signal System with in-house PCR and culture for detection of Mycobacterium tuberculosis in respiratory specimens. J Clin Microbiol 1996; 34: 3092-3096.

22. Yuen KY, Yam WC, Wong LP, Seto WH. Comparison of two automated DNA amplification systems with a manual one-tube nested PCR assay for diagnosis of pulmonary tuberculosis. J Clin Microbiol 1997; 35: 1385-1389.

23. Wang SX, Tay L. Evaluation of three nucleic acid amplification methods for direct detection of Mycobacterium tuberculosis complex in respiratory specimens. J Clin Microbiol 1999;37:1932-4.

24. Gomez-Pastrana D, Torronteras R, Caro P, Anguita ML, Lopez-Barrio AM, Andres A, Navarro J. Comparison of amplicor, in-house polymerase chain reaction, and conventional culture for the diagnosis of tuberculosis in children. Clin Infect Dis. 2001;32:17-22.

25. Kang EY, Choi JA, Seo BK, Oh YW, Lee CK, Shim JJ. Utility of polymerase chain reaction for detecting Mycobacterium tuberculosis in specimens from percutaneous transthoracic needle aspiration. Radiology 2002;225:205-9.

26. Kidane D, Olobo JO, Habte A, Negesse Y, Aseffa A, Abate G, Yassin MA, Bereda K, Harboe M. Identification of the causative organism of tuberculous lymphadenitis in ethiopia by PCR. J Clin Microbiol 2002;40:4230-4.

27. Bruijnesteijn Van Coppenraet ES, Lindeboom JA, Prins JM, Peeters MF, Claas EC, 
Kuijper EJ. Real-time PCR assay using fine-needle aspirates and tissue biopsy specimens for rapid diagnosis of mycobacterial lymphadenitis in children. $J$ Clin Microbiol 2004;42:2644-50.

28. Querol JM, Minguez J, Garcia-Sanchez E, Farga MA, Gimeno C, Garcia-de-Lomas J. Rapid diagnosis of pleural tuberculosis by polymerase chain reaction. Am J Respir Crit Care Med 1995;152:1977-81.

29. Mitarai S, Shishido H, Kurashima A, Tamura A, Nagai H. Comparative study of amplicor Mycobacterium PCR and conventional methods for the diagnosis of pleuritis caused by mycobacterial infection. Int J Tuberc Lung Dis 2000; 4: 871876.

30. Villegas MV, Labrada LA, Saravia NG. Evaluation of polymerase chain reaction, adenosine deaminase, and interferon-gamma in pleural fluid for the differential diagnosis of pleural tuberculosis. Chest 2000; 118: 1355-1364.

31. Nagesh BS, Sehgal S, Jindal SK, Arora SK. Evaluation of polymerase chain reaction for detection of Mycobacterium tuberculosis in pleural fluid. Chest 2001;119:173741.

32. Pai M, Flores LL, Hubbard A, Riley LW, Colford JM Jr. Nucleic acid amplification tests in the diagnosis of tuberculous pleuritis: a systematic review and meta-analysis. BMC Infect Dis 2004;4:6.

33. Hasaneen NA, Zaki ME, Shalaby HM, El-Morsi AS. Polymerase chain reaction of pleural biopsy is a rapid and sensitive method for the diagnosis of tuberculous pleural effusion. Chest 2003;124:2105-11.

34. Lang AM, Feris-Iglesias J, Pena C, Sanchez JF, Stockman L, Rys P, Roberts GD, 
35. Desai MM, Pal RB. Polymerase chain reaction for the rapid diagnosis of tuberculous meningitis. Indian J Med Sci 2002;56:546-52.

36. Jonsson B, Ridell M. The Cobas Amplicor MTB test for detection of Mycobacterium tuberculosis complex from respiratory and non-respiratory clinical specimens. Scand J Infect Dis 2003; 35: 372-377.

37. Pai M, Flores LL, Pai N, Hubbard A, Riley LW, Colford JM Jr. Diagnostic accuracy of nucleic acid amplification tests for tuberculous meningitis: a systematic review and meta-analysis. Lancet Infect Dis 2003;3:633-43.

38. Diaz ML, Herrera T, Lopez-Vidal Y, Calva JJ, Hernandez R, Palacios GR, Sada E. Polymerase chain reaction for the detection of Mycobacterium tuberculosis DNA in tissue and assessment of its utility in the diagnosis of hepatic granulomas. J Lab Clin Med 1996;127:359-63.

39. Alcantara-Payawal DE, Matsumura M, Shiratori Y, Okudaira T, Gonzalez R, Lopez RA, Sollano JD, Omata M. Direct detection of Mycobacterium tuberculosis using polymerase chain reaction assay among patients with hepatic granuloma. J Hepatol $1997 ; 27: 620-7$.

40. Moussa OM, Eraky I, El-Far MA, Osman HG, Ghoneim MA. Rapid diagnosis of genitourinary tuberculosis by polymerase chain reaction and non-radioactive DNA hybridization. J Urol 2000;164:584-8.

41. Kafwabulula M, Ahmed K, Nagatake T, Gotoh J, Mitarai S, Oizumi K, Zumla A. 
Evaluation of PCR-based methods for the diagnosis of tuberculosis by identification of mycobacterial DNA in urine samples. Int J Tuberc Lung Dis 2002;6:732-7.

42. Arora SK, Kumar B, Sehgal S. Development of a polymerase chain reaction dotblotting system for detecting cutaneous tuberculosis. Br J Dermatol 2000;142:72-6.

43. Quiros E, Bettinardi A, Quiros A, Piedrola G, Maroto MC. Detection of mycobacterial DNA in papulonecrotic tuberculid lesions by polymerase chain reaction. J Clin Lab Anal 2000;14:133-5.

44. Schluger NW, Condos R, Lewis S, Rom WN. Amplification of DNA of Mycobacterium tuberculosis from peripheral blood of patients with pulmonary tuberculosis. Lancet 1994;344:232-3.

45. Folgueira L, Delgado R, Palenque E, Aguado JM, Noriega AR. Rapid diagnosis of Mycobacterium tuberculosis bacteremia by PCR. J Clin Microbiol 1996;34:512-5.

46. Honore S, Vincensini JP, Hocqueloux L, Noguera ME, Farge D, Lagrange P, Herrmann JL. Diagnostic value of a nested polymerase chain reaction assay on peripheral blood mononuclear cells from patients with pulmonary and extrapulmonary tuberculosis. Int J Tuberc Lung Dis 2001;5:754-62.

47. Lombard EH, Victor T, Jordaan A, van Helden PD. The detection of Mycobacterium tuberculosis in bone marrow aspirate using the polymerase chain reaction. Tuber Lung Dis 1994;75:65-9.

48. Akcan Y, Tuncer S, Hayran M, Sungur A, Unal S. PCR on disseminated tuberculosis in bone marrow and liver biopsy specimens: correlation to histopathological and clinical diagnosis. Scand J Infect Dis 1997;29:271-4.

49. Sumi MG, Mathai A, Sheela R, Radhakrishnan NS, Radhakrishnan VV, 
Indhulekshmy R, Mundayoor S. Diagnostic utility of polymerase chain reaction and immunohistochemical techniques for the laboratory diagnosis of intracranial tuberculoma. Clin Neuropathol 2001;20:176-80.

50. Park do Y, Kim JY, Choi KU, Lee JS, Lee CH, Sol MY, Suh KS. Comparison of polymerase chain reaction with histopathologic features for diagnosis of tuberculosis in formalin-fixed, paraffin-embedded histologic specimens. Arch Pathol Lab Med 2003;127:326-30.

51. Pfyffer GE, Kissling P, Jahn EM, Welscher HM, Salfinger M, Weber R. Diagnostic performance of amplified Mycobacterium tuberculosis direct test with cerebrospinal fluid, other nonrespiratory, and respiratory specimens. J Clin Microbiol. 1996;34:834-41.

52. Bergmann JS, Keating WE, Woods GL. Clinical evaluation of the BDProbeTec ET system for rapid detection of Mycobacterium tuberculosis. J Clin Microbiol 2000; 38: 863-865.

53. Maugein J, Fourche J, Vacher S, Grimond C, Bebear C. Evaluation of the BDProbeTec ET DTB assay (1) for direct detection of Mycobacterium tuberculosis complex from clinical samples. Diagn Microbiol Infect Dis 2002; 44: 151-155.

54. Rusch-Gerdes S, Richter E. Clinical evaluation of the semiautomated BDProbeTec ET System for the detection of Mycobacterium tuberculosis in respiratory and nonrespiratory specimens. Diagn Microbiol Infect Dis. 2004;48:265-70.

55. Piersimoni C, Scarparo C, Piccoli P, Rigon A, Ruggiero G, Nista D, Bornigia S. Performance assessment of two commercial amplification assays for direct detection of Mycobacterium tuberculosis complex from respiratory and extrapulmonary 
specimens. J Clin Microbiol 2002; 40: 4138-4142.

56. Jesus de la Calle I, Jesus de la Calle MA, Rodriguez-Iglesias M. Evaluation of the BDProbeTec ET system as screening tool in the direct detection of mycobacterium tuberculosis complex in respiratory specimens. Diagn Microbiol Infect Dis 2003; 47: 573-578.

57. Johansen IS, Lundgren B, Tabak F, Petrini B, Hosoglu S, Saltoglu N, Thomsen VO. Improved sensitivity of nucleic acid amplification for rapid diagnosis of tuberculous meningitis. J Clin Microbiol 2004; 42: 3036-3040.

58. Dowdy DW, Maters A, Parrish N, Beyrer C, Dorman SE. Cost-effectiveness analysis of the gen-probe amplified mycobacterium tuberculosis direct test as used routinely on smear-positive respiratory specimens. J Clin Microbiol 2003; 41: 948953.

59. Boddinghaus B, Wichelhaus TA, Brade V, Bittner T. Removal of PCR inhibitors by silica membranes: evaluating the Amplicor Mycobacterium tuberculosis kit. J Clin Microbiol 2001;39:3750-2.

60. Fernstrom MC, Dahlgren L, Ranby M, Forsgren A, Petrini B. Increased sensitivity of Mycobacterium tuberculosis Cobas Amplicor PCR following brief incubation of tissue samples on Lowenstein-Jensen substrate. APMIS. 2003;111:1114-6.

61. Noordhoek GT, van Embden JD, Kolk AH. Reliability of nucleic acid amplification for detection of Mycobacterium tuberculosis: an international collaborative quality control study among 30 laboratories. J Clin Microbiol. 1996;34:2522-5.

62. Yuen KY, Chan KS, Chan CM, Ho PL, Ng MH. Monitoring the therapy of pulmonary tuberculosis by nested polymerase chain reaction assay. J Infect 
1997;34:29-33.

63. Cheng VC, Yam WC, Hung IF, Woo PC, Lau SK, Tang BS, Yuen KY. Clinical evaluation of the polymerase chain reaction for the rapid diagnosis of tuberculosis. $J$ Clin Pathol 2004;57:281-5.

64. Woods GL. The mycobacteriology laboratory and new diagnostic techniques. Infect Dis Clin North Am 2002; 16: 127-144.

65. Patel JB, Leonard DG, Pan X, Musser JM, Berman RE, Nachamkin I. Sequencebased identification of Mycobacterium species using the MicroSeq 500 16S rDNA bacterial identification system. J Clin Microbiol. 2000;38:246-51.

66. Cloud JL, Neal H, Rosenberry R, Turenne CY, Jama M, Hillyard DR, Carroll KC. Identification of Mycobacterium spp. by using a commercial 16S ribosomal DNA sequencing kit and additional sequencing libraries. J Clin Microbiol. 2002;40:400-6.

67. Hall L, Doerr KA, Wohlfiel SL, Roberts GD. Evaluation of the MicroSeq system for identification of mycobacteria by $16 \mathrm{~S}$ ribosomal DNA sequencing and its integration into a routine clinical mycobacteriology laboratory. J Clin Microbiol. 2003;41:144753.

68. Scarparo C, Piccoli P, Rigon A, Ruggiero G, Nista D, Piersimoni C. Direct identification of mycobacteria from $\mathrm{MB} / \mathrm{BacT}$ alert 3D bottles: comparative evaluation of two commercial probe assays. J Clin Microbiol. 2001;39:3222-7.

69. Miller N, Infante S, Cleary T. Evaluation of the LiPA MYCOBACTERIA assay for identification of mycobacterial species from BACTEC 12B bottles. $J$ Clin Microbiol. 2000;38:1915-9.

70. Sarkola A, Makinen J, Marjamaki M, Marttila HJ, Viljanen MK, Soini H 
Prospective evaluation of the GenoType assay for routine identification of mycobacteria. Eur J Clin Microbiol Infect Dis. 2004;23:642-5.

71. Lebrun L, Gonullu N, Boutros N, Davoust A, Guibert M, Ingrand D, Ghnassia JC, Vincent V, Doucet-Populaire F. Use of INNO-LIPA assay for rapid identification of mycobacteria. Diagn Microbiol Infect Dis 2003; 46: 151-153.

72. Padilla E, Gonzalez V, Manterola JM, Perez A, Quesada MD, Gordillo S, Vilaplana C, Pallares MA, Molinos S, Sanchez MD, Ausina V. Comparative evaluation of the new version of the INNO-LiPA Mycobacteria and genotype Mycobacterium assays for identification of Mycobacterium species from $\mathrm{MB} / \mathrm{Bac} \mathrm{T}$ liquid cultures artificially inoculated with Mycobacterial strains. J Clin Microbiol 2004; 42: 30833088.

73. Tortoli E, Nanetti A, Piersimoni C, Cichero P, Farina C, Mucignat G, Scarparo C, Bartolini L, Valentini R, Nista D, Gesu G, Tosi CP, Crovatto M, Brusarosco G. Performance assessment of new multiplex probe assay for identification of mycobacteria. J Clin Microbiol. 2001;39:1079-84.

74. Tortoli E, Mariottini A, Mazzarelli G. Evaluation of INNO-LiPA MYCOBACTERIA v2: improved reverse hybridization multiple DNA probe assay for mycobacterial identification. J Clin Microbiol. 2003;41:4418-20.

75. Kim BJ, Lee KH, Park BN, Kim SJ, Bai GH, Kim SJ, Kook YH. Differentiation of mycobacterial species by PCR-restriction analysis of DNA (342 base pairs) of the RNA polymerase gene (rpoB). J Clin Microbiol 2001; 39: 2102-2109.

76. Troesch A, Nguyen H, Miyada CG, Desvarenne S, Gingeras TR, Kaplan PM, Cros P, Mabilat C. Mycobacterium species identification and rifampin resistance testing 
with high-density DNA probe arrays. J Clin Microbiol 1999; 37: 49-55.

77. Fukushima M, Kakinuma K, Hayashi H, Nagai H, Ito K, Kawaguchi R. Detection and identification of Mycobacterium species isolates by DNA microarray. J Clin Microbiol 2003; 41: 2605-2615.

78. Hongmanee P, Stender H, Rasmussen OF. Evaluation of a fluorescence in situ hybridization assay for differentiation between tuberculous and nontuberculous Mycobacterium species in smears of Lowenstein-Jensen and Mycobacteria Growth Indicator Tube cultures using peptide nucleic acid probes. J Clin Microbiol 2001; 39: 1032-1035.

79. Zerbi P, Schonau A, Bonetto S, Gori A, Costanzi G, Duca P, Vago L. Amplified in situ hybridization with peptide nucleic acid probes for differentiation of Mycobacterium tuberculosis complex and nontuberculous Mycobacterium species on formalin-fixed, paraffin-embedded archival biopsy and autopsy samples. Am J Clin Pathol 2001; 116: 770-775.

80. Wade MM, Zhang Y. Mechanisms of drug resistance in Mycobacterium tuberculosis. Front Biosci 2004; 9: 975-994.

81. Kim BJ, Lee KH, Park BN, Kim SJ, Park EM, Park YG, Bai GH, Kim SJ, Kook YH. Detection of rifampin-resistant Mycobacterium tuberculosis in sputa by nested PCR-linked single-strand conformation polymorphism and DNA sequencing. J Clin Microbiol 2001; 39: 2610-2617.

82. Nash KA, Gaytan A, Inderlied CB. Detection of rifampin resistance in Mycobacterium tuberculosis by use of a rapid, simple, and specific RNA/RNA mismatch assay. J Infect Dis 1997; 176: 533-536. 
83. Piana A, Orru M, Masia MD, Sotgiu G, Muresu E, Maida A. Detection of isoniazid and rifampin resistance in Mycobacterium tuberculosis strains by single-strand conformation polymorphism analysis and restriction fragment length polymorphism. New Microbiol 2003; 26: 375-381.

84. Yue J, Shi W, Xie J, Li Y, Zeng E, Liang L, Wang H. Detection of rifampinresistant Mycobacterium tuberculosis strains by using a specialized oligonucleotide microarray. Diagn Microbiol Infect Dis 2004; 48: 47-54.

85. Watterson SA, Wilson SM, Yates MD, Drobniewski FA. Comparison of three molecular assays for rapid detection of rifampin resistance in Mycobacterium tuberculosis. J Clin Microbiol 1998; 36: 1969-1973.

86. Ruiz M, Torres MJ, Llanos AC, Arroyo A, Palomares JC, Aznar J. Direct detection of rifampin- and isoniazid-resistant Mycobacterium tuberculosis in auraminerhodamine-positive sputum specimens by real-time PCR. J Clin Microbiol 2004; 42: $1585-1589$.

87. Mikhailovich V, Lapa S, Gryadunov D, Sobolev A, Strizhkov B, Chernyh N, Skotnikova O, Irtuganova O, Moroz A, Litvinov V, Vladimirskii M, Perelman M, Chernousova L, Erokhin V, Zasedatelev A, Mirzabekov A. Identification of rifampin-resistant Mycobacterium tuberculosis strains by hybridization, PCR, and ligase detection reaction on oligonucleotide microchips. J Clin Microbiol 2001; 39: 2531-2540.

88. Leone G, van Schijndel H, van Gemen B, Kramer FR, Schoen CD. Molecular beacon probes combined with amplification by NASBA enable homogeneous, realtime detection of RNA. Nucleic Acids Res 1998; 26: 2150-2155. 
89. El-Hajj HH, Marras SA, Tyagi S, Kramer FR, Alland D. Detection of rifampin resistance in Mycobacterium tuberculosis in a single tube with molecular beacons. $J$ Clin Microbiol 2001; 39: 4131-4137.

90. Bockstahler LE, Li Z, Nguyen NY, Van Houten KA, Brennan MJ, Langone JJ, Morris SL. Peptide nucleic acid probe detection of mutations in Mycobacterium tuberculosis genes associated with drug resistance. Biotechniques 2002; 32: 508510, 512, 514 .

91. Alland D, Kalkut GE, Moss AR, McAdam RA, Hahn JA, Bosworth W, Drucker E, Bloom BR. Transmission of tuberculosis in New York City. An analysis by DNA fingerprinting and conventional epidemiologic methods. $N$ Engl $J$ Med 1994;330:1710-6.

92. Gascoyne-Binzi DM, Barlow RE, Frothingham R, Robinson G, Collyns TA, Gelletlie R, Hawkey PM. Rapid identification of laboratory contamination with Mycobacterium tuberculosis using variable number tandem repeat analysis. J Clin Microbiol 2001;39:69-74.

93. Edlin BR, Tokars JI, Grieco MH, Crawford JT, Williams J, Sordillo EM, Ong KR, Kilburn JO, Dooley SW, Castro KG. An outbreak of multidrug-resistant tuberculosis among hospitalized patients with the acquired immunodeficiency syndrome. $N$ Engl J Med 1992;326:1514-21.

94. van Soolingen D, de Haas PE, Hermans PW, Groenen PM, van Embden JD. Comparison of various repetitive DNA elements as genetic markers for strain differentiation and epidemiology of Mycobacterium tuberculosis. J Clin Microbiol. 1993;31:1987-95. 
95. Spurgiesz RS, Quitugua TN, Smith KL, Schupp J, Palmer EG, Cox RA, Keim P. Molecular typing of Mycobacterium tuberculosis by using nine novel variablenumber tandem repeats across the Beijing family and low-copy-number IS6110 isolates. J Clin Microbiol 2003;41:4224-30.

96. Rhee JT, Tanaka MM, Behr MA, Agasino CB, Paz EA, Hopewell PC, Small PM. Use of multiple markers in population-based molecular epidemiologic studies of tuberculosis. Int J Tuberc Lung Dis 2000; 4: 1111-1119.

97. Liebana E, Aranaz A, Francis B, Cousins D. Assessment of genetic markers for species differentiation within the Mycobacterium tuberculosis complex. J Clin Microbiol 1996; 34: 933-938.

98. Filliol I, Ferdinand S, Negroni L, Sola C, Rastogi N. Molecular typing of Mycobacterium tuberculosis based on variable number of tandem DNA repeats used alone and in association with spoligotyping. J Clin Microbiol. 2000;38:2520-4.

99. Goguet de la Salmoniere YO, Li HM, Torrea G, Bunschoten A, van Embden J, Gicquel B. Evaluation of spoligotyping in a study of the transmission of Mycobacterium tuberculosis. J Clin Microbiol. 1997;35:2210-4.

100. Miller N, Cleary T, Kraus G, Young AK, Spruill G, Hnatyszyn HJ. Rapid and specific detection of Mycobacterium tuberculosis from acid-fast bacillus smearpositive respiratory specimens and BacT/ALERT MP culture bottles by using fluorogenic probes and real-time PCR. J Clin Microbiol 2002;40:4143-7.

101. Desjardin LE, Perkins MD, Wolski K, Haun S, Teixeira L, Chen Y, Johnson JL, Ellner JJ, Dietze R, Bates J, Cave MD, Eisenach KD. Measurement of sputum Mycobacterium tuberculosis messenger RNA as a surrogate for response to 
chemotherapy. Am J Respir Crit Care Med 1999;160:203-10.

102. Cole ST, Brosch R, Parkhill J, Garnier T, Churcher C, Harris D, Gordon SV, Eiglmeier K, Gas S, Barry CE 3rd, Tekaia F, Badcock K, Basham D, Brown D, Chillingworth T, Connor R, Davies R, Devlin K, Feltwell T, Gentles S, Hamlin N, Holroyd S, Hornsby T, Jagels K, Krogh A, McLean J, Moule S, Murphy L, Oliver K, Osborne J, Quail MA, Rajandream MA, Rogers J, Rutter S, Seeger K, Skelton J, Squares R, Squares S, Sulston JE, Taylor K, Whitehead S, Barrell BG. Deciphering the biology of Mycobacterium tuberculosis from the complete genome sequence. Nature. 1998;393:537-44.

103. Ragno S, Romano M, Howell S, Pappin DJ, Jenner PJ, Colston MJ. Changes in gene expression in macrophages infected with Mycobacterium tuberculosis: a combined transcriptomic and proteomic approach. Immunology. 2001;104:99-108.

104. Selvaraj P, Chandra G, Jawahar MS, Rani MV, Rajeshwari DN, Narayanan PR. Regulatory role of vitamin D receptor gene variants of Bsm I, Apa I, Taq I, and Fok I polymorphisms on macrophage phagocytosis and lymphoproliferative response to mycobacterium tuberculosis antigen in pulmonary tuberculosis. J Clin Immunol. 2004;24:523-32.

105. Uma H, Selvaraj P, Reetha AM, Xavier T, Prabhakar R, Narayanan PR. Influence of HLA-DR antigens on lymphocyte response to Mycobacterium tuberculosis culture filtrate antigens and mitogens in pulmonary tuberculosis. Tuber Lung Dis. 1999;79:199-206.

106. Shams H, Klucar P, Weis SE, Lalvani A, Moonan PK, Safi H, Wizel B, Ewer K, Nepom GT, Lewinsohn DM, Andersen P, Barnes PF. Characterization of a 
Mycobacterium tuberculosis peptide that is recognized by human CD4+ and CD8+ T cells in the context of multiple HLA alleles. J Immunol. 2004;173:1966-77.

107. Bellamy R, Ruwende C, Corrah T, McAdam KP, Whittle HC, Hill AV. Variations in the NRAMP1 gene and susceptibility to tuberculosis in West Africans. $N$ Engl $J$ Med 1998;338:640-4.

108. Lopez-Maderuelo D, Arnalich F, Serantes R, Gonzalez A, Codoceo R, Madero R, Vazquez JJ, Montiel C. Interferon-gamma and interleukin-10 gene polymorphisms in pulmonary tuberculosis. Am J Respir Crit Care Med 2003;167:970-5. 
Table 1. Overview of sensitivity and specificity of polymerase chain reaction using either in-house or commercial methods in detection of Mycobacterium tuberculosis from direct clinical specimens

\begin{tabular}{|c|c|c|c|}
\hline & $\begin{array}{l}\text { Overall sensitivity } \\
\qquad(\%)^{!}\end{array}$ & $\begin{array}{l}\text { Overall specificity } \\
\text { (\%) }\end{array}$ & Ref \\
\hline \multicolumn{4}{|l|}{ Anatomical site } \\
\hline Respiratory specimens* & $77.1-100$ & $99.3-100$ & 22,23 \\
\hline Gastric aspirates & $44-60$ & $93.7-98$ & 24 \\
\hline PTNA ${ }^{@}$ & 65 & 100 & 25 \\
\hline \multicolumn{4}{|l|}{ Extrapulmonary } \\
\hline $\begin{array}{l}\text { Lymph node } \\
\text { (fresh tissue) }\end{array}$ & $71.6-87.5$ & NM & $26,27^{\$}$ \\
\hline Pleural fluid & $27.3-81$ & $90-100$ & $28-32$ \\
\hline Pleural biopsy & 90 & 100 & 33 \\
\hline Cerebrospinal fluid & $31.4-56$ & 98 & $34-37$ \\
\hline CAPD fluid & CR & CR & \\
\hline Ascite fluid & CR & CR & \\
\hline $\begin{array}{l}\text { Liver biopsy tissue } \\
\text { (paraffin-embedded) }\end{array}$ & $58-88$ & $96-100$ & 38,39 \\
\hline Urine & $55.6-95.6$ & $98.1-98.9$ & 40,41 \\
\hline Skin & $60-80$ & 100 & 42,43 \\
\hline Bone \& synovial tissue & $\mathrm{CR}$ & CR & \\
\hline Peripheral blood & $30.4-100^{\#}$ & NM & $44-46$ \\
\hline Marrow blood & $42-73.2$ & NM & 47,48 \\
\hline Paraffin-embedded tissues & $60-68$ & NM & 49,50 \\
\hline
\end{tabular}

Note. 'Mycobacterium tuberculosis culture as gold standard for respiratory specimens whereas clinical diagnosis with or without radiological and histological findings as gold standard for other specimens; * sputum, bronchoalveolar lavage fluid, endotracheal aspirates; @ Percutaneous transthoracic needle aspiration " 82\% in HIV-positive; \$ Real-time PCR is performed; CR, case report only; NM, not mentioned; PCR, polymerase chain reaction; Ref, references 